\title{
Neuroprotective effects of seaweeds against 6-hydroxidopamine-induced cell death on an in vitro human neuroblastoma model
}

\author{
Joana Silva ${ }^{1,2}$, Celso Alves ${ }^{1}$, Susete Pinteus ${ }^{1}$, Susana Mendes ${ }^{1}$ and Rui Pedrosa ${ }^{1 *}$
}

\begin{abstract}
Background: Parkinson's disease (PD) is a progressive neurodegenerative disorder of the central nervous system. Although the causes of PD pathogenesis remain incomplete, some evidences has suggested that oxidative stress is an important mediator in its pathogenesis. The aim of this study was to evaluate the protective effects of seaweeds with high antioxidant activity on 6-hydroxydopamine (6-OHDA)-induced neurotoxicity in the human neuroblastoma cell line SH-SY5Y, as well as the associated intracellular signaling pathways.

Methods: Cell viability studies were assessed by 3-(4,5-dimethylthiazol-2yl)-2,5-diphenyltetrazolium (MTT) bromide assay and the intracellular signaling pathways analyzed were: hydrogen peroxide $\left(\mathrm{H}_{2} \mathrm{O}_{2}\right)$ production, changes in the mitochondrial membrane potential and Caspase-3 activity.

Results: Exposure of SH-SY5Y cells to 6-OHDA (10-1000 $\mu \mathrm{M})$ reduced cell's viability in a concentration and timedependent manner. The data suggest that the cell death induced by 6-OHDA was mediated by an increase of $\mathrm{H}_{2} \mathrm{O}_{2}$ production, the depolarization of mitochondrial membrane potential and the increase of Caspase-3 activity. Extracts from S. polyshides, P. pavonica, S. muticum, C. tomentosum and U. compressa revealed to efficiently protect cell's viability in the presence of 6-OHDA (100 $\mu \mathrm{M} ; 24 \mathrm{~h}$ ). These effects appear to be associated with the reduction of $\mathrm{H}_{2} \mathrm{O}_{2}$ cell's production, the protection of mitochondrial membrane's potential and the reduction of Caspase-3 activity.
\end{abstract}

Conclusions: These results suggest that seaweeds can be a promising source of new compounds with neuroprotective potential.

Keywords: Parkinson's disease, Substantia nigra, Mitochondrial membrane potential, Caspase - 3 activity, Oxidative stress, Apoptosis, Marine natural bioactive compounds

\section{Background}

Currently with the increasing of life expectancy and the demographic changes in population, neurodegenerative diseases, such as Alzheimer's and Parkinson's disease (PD) are becoming frighteningly common $[1,2]$.

$\mathrm{PD}$ is a progressive neurodegenerative disorder of unknown etiology that is characterized by a progressive loss of dopaminergic neurons in substantia nigra pars compacta (SNpc) that underlie characteristic motor symptoms such as rigidity, tremor, slowness of movement, and postural abnormalities [3]. Neuropathology of

\footnotetext{
* Correspondence: rpedrosa@ipleiria.pt

${ }^{1}$ MARE - Marine and Environmental Sciences Centre, ESTM, Instituto

Politécnico de Leiria, 2520-641 Peniche, Portugal

Full list of author information is available at the end of the article
}

PD includes insufficient striatal dopamine formation and activity, arising from the death of dopaminergic neurons in SNpc region of the brain. Although the causes of PD pathogenesis remains incomplete, considerable evidences from human and animal studies have suggested that many pathological mechanisms such as oxidative stress, mitochondrial and lysosomal dysfunctions, neuroinflammatory processes, and the formation of pathologic inclusions, contribute to neuronal death $[4,5]$. In fact, the nigral dopaminergic neurons are rich in reactive oxygen species (ROS) due to the auto-oxidization of dopamine at normal $\mathrm{pH}$ producing toxic dopamine-quinone species, superoxide radicals $\left(\mathrm{O}_{2}^{*-}\right)$, hydrogen peroxide $\left(\mathrm{H}_{2} \mathrm{O}_{2}\right)$, and hydroxyl radicals $\left(\bullet^{\circ} \mathrm{OH}\right)$. This is supported by increased levels of oxidative products of lipids, 
proteins, and DNA verified in the substantia nigra of PD patients [6]. The pharmacologic treatment of PD can be divided into symptomatic and neuroprotective therapies. The aim of symptomatic strategy is to counteract the deficiency of dopamine in the basal ganglia or to block muscarinic receptors. By other side, the neuroprotective therapy aims to slow, block, or reverse the disease progression. However, such therapies are defined as those that slow the underlying loss of dopaminergic neurons. In fact, at this time, there are no completely proven neuroprotective or disease-modifying therapies [5].

The neurotoxin 6-Hydroxydopamine (6-OHDA) is widely used to mimic experimental models of PD since it can selectively damage dopaminergic neurons in vivo and in vitro. 6-OHDA has a similar structure to dopamine and shows high affinity for the dopamine transporter, therefore it selectively destroys dopaminergic/ catecholaminergic neurons $[7,8]$. Once inside the neuron, 6-OHDA accumulates and undergoes nonenzymatic auto-oxidation, promoting reactive oxygen species formation. Furthermore, 6-OHDA may provoke the inhibition of mitochondrial complexes I and IV, causing the adenosine triphosphate (ATP) depletion. These evidences suggest the hypothesis that oxidative stress and mitochondrial dysfunction are responsible for the cell death induced by 6 -OHDA $[9,10]$. In addition, human neuroblastoma SH-SY5Y is a dopaminergic neuronal cell line which has been used as an in vitro model for the study of PD and to determine the effect of protective and therapeutic agents. These cells have become a popular research cell model for PD due to the high similarity with dopaminergic neurons [11-14]. The increasing evidences that oxidative stress is critically involved in the pathogenesis of PD suggest that pharmacological targeting of the antioxidant machinery may have therapeutic value [15]. In addition, several experiments revealed that therapies including the intake of synthetic and natural antioxidants have shown a protective effect on the degeneration of dopaminergic neurons $[6,16-19]$. Moreover, different studies indicate that the intake of dietary food with high antioxidants content can lower the associated risk of PD [20-24].

The marine environment is known as a rich source of chemical structures with numerous beneficial health effects. It is widely accepted that marine natural products provide unusual and unique chemical structures upon which molecular modeling and chemical synthesis of new drugs can be based with greater efficacy and specificity for the treatment of human diseases [25-27]. Among marine organisms, seaweeds have been target of numerous studies that show their potential as a rich source of structurally diverse biologically active compounds with great pharmaceutical and biomedical potential [28]. Recently, several scientific studies have provided an insight into biological activities and neuroprotective effects of marine algae including antioxidant, anti-neuroinflammatory, cholinesterase inhibitory activity and the inhibition of neuronal death suggesting that marine algae have great potential to be used for neuroprotection as part of pharmaceuticals, nutraceuticals and functional foods [28-30]. In line with this, the main aim of the present study was to investigate the protective effects of seaweeds extracts on 6-hydroxydopamine (6-OHDA)-induced neurotoxicity in the human neuroblastoma cell line SH-SY5Y and the intracellular signaling pathways involved in such effects.

\section{Methods}

Collection and identification of algae extracts

Seaweeds were collect freshly, between April and July of 2013, in Papôa (39 $22^{\prime} 09.5^{\prime \prime} \mathrm{N} 9^{\circ} 22^{\prime} 40.4$ W), Quebrado $\left(39^{\circ} 22^{\prime} 04.6^{\prime \prime} \mathrm{N} 9^{\circ} 22^{\prime} 26.1 \mathrm{~W}\right)$ and Gamboa (39 $21^{\prime} 54.3^{\prime \prime}$ N 9'22'22.7") beaches, Peniche (Portugal) and immediately transported to laboratory. The seaweeds were then washed with seawater to remove epiphytes, detritus and encrusting material. Algae were identified as Padina pavonica, Sargassum muticum, Saccorhiza polyschides (Heterokontophyta division); Codium tomentosum, and Ulva compressa (Chlorophyta division). Identification was performed by Dr. Susete Pinteus, supported by Marine Algae: Biodiversity, Taxonomy, Environmental Assessment, and Biotechnology guide [31]. Finally algae were kept at $-80{ }^{\circ} \mathrm{C}$ (Thermo Scientific, Electron Corporation, Waltham, Massachusetts, USA) until extraction process.

\section{Preparation of seaweed extracts}

Freeze dried seaweeds were sequentially extracted in a 1:40 biomass:solvent ratio with methanol (>99\%, VWR, 20,903.368, Fontenay-sous-Bois, France) and dichloromethane (99\%, Fischer Scientifc, D/1852/21/, Loughborough, United Kingdom) at constant stirring for $12 \mathrm{~h}$. Liquid-liquid extraction was also performed for the methanolic fraction, using n-Hexane (99\%, Fischer Scientifc, D/1852/21/, Loughborough, United Kingdom). The solvents were evaporated in a rotary evaporator (Laborota 4000, Heidolph, Schwabach, Germany) at $40{ }^{\circ} \mathrm{C}$ and the biomass obtained was then solubilized in dimethyl sulfoxide (DMSO) (Sigma Aldrich, 274,380, Saint louis, USA) and stored at $-20^{\circ} \mathrm{C}$ until further use.

\section{Cell culture}

The experiments were performed on human neuroblastoma (SH-SY5Y cells), from DMSZ bank - German collection of microorganisms and cell cultures (ACC 209) and maintained with Dulbecco's Modified Eagle's Medium (DMEM) (Sigma - Aldrich, D8900, Steinheim am Albuch, Germany) supplemented with $20 \%(v / v)$ of 
fetal bovine serum (FBS) (Hyclone, SV30160.0, Northumherlan, UK) and 1\% of antibiotic/antimycotic commercial solution (Hyclone, SV30079.01, Utah, USA). For subcultures, SH-SY5Y cells were dissociated with tripsin-EDTA (Hyclone, Thermoscientific, SV30031.01, Waltham Massachusetts, USA), split into a 1:3 ratio and subcultured into Petri dishes with $25 \mathrm{~cm}^{2}$ growth area. Medium was replaced every 2 days until the cells reached the total confluence (4-5 days of initial seeding). Cells were maintained in the following controlled conditions: $95 \%$ of humidified atmosphere, $5 \%$ of $\mathrm{CO}_{2}$ and constant temperature of $37^{\circ} \mathrm{C}$.

\section{Evaluation of neurotoxicity effects induced by 6-OHDA on SH-SY5Y cells viability}

The neurotoxicity induced by 6-OHDA (Sigma Aldrich, H4381 Steinheim am Albuch Germany) on SHSY5Y cells was evaluated in 96 well plates after the cells reached total confluence. The cells were then incubated with different concentrations of 6-OHDA (10, 30, 100, 300 and $1000 \mu \mathrm{M})$ during $24 \mathrm{~h}$. The time-course effects of 6-OHDA (100, 300 and $1000 \mu \mathrm{M})$ were also studied after 12,24 and $48 \mathrm{~h}$ of incubation. The solutions were previous prepared in culture medium without FBS and sterile filtered $(0.2 \mu \mathrm{m})$ (Whatman, Maidstone, UK). The effects were assessed by a colorimetric assay $(570 \mathrm{~nm})$ based on the conversion of tetrazolium salts (MTT) (Amresco, 0793-1G, Solon, USA) to blue formazan products by active mitochondria [32, 33]. Results were expressed in percentage of control and as $\mathrm{IC}_{50}$ (concentration causing $50 \%$ of cell viability reduction) where applicable.

\section{Cytotoxicity and protective effects of seaweeds extracts on neurotoxicity induced by 6-OHDA}

A previous work from our work group screened twenty seven seaweeds for their antioxidant potential, revealing 12 extracts with high antioxidant activity [34]. Within these, only 6 fractions didn't exhibit toxicity on SHSY5Y cells (data not shown) being selected for the neuroprotective assays, namely: methanolic extracts Sargassum muticum, Sacchorhiza polyshides, Padina pavonica; dichloromethane extracts - Sargassum muticum, Codium tomentosum and Ulva compressa. The neuroprotective effect of seaweeds extracts on SH-SY5Y cells in the presence of 6-OHDA was tested after cells reached total confluence in 96 well plates. Cells were incubated with 6-OHDA $(100 \mu \mathrm{M})$ and seaweeds extracts (1 mg/mL) during $24 \mathrm{~h}$.

\section{MTT method}

The solutions were previously prepared in culture medium without FBS and sterile filtered $(0.2 \mu \mathrm{m})$. The effects were estimated by colorimetric assay $(570 \mathrm{~nm})$ based on the conversion of tetrazolium salts (MTT) to a blue formazan product by active mitochondria [32, 33]. Results were expressed in percentage of control.

\section{Calcein -AM method}

This method is based on the fluorophore calcein-AM (Invitrogen, C31100MP, Waltham, Massachusetts, USA). The calcein, in its natural form, exhibits fluorescence; however once esterified (calcein-AM) loses this feature and gain the ability to penetrate cell's membranes. Within this, the esterase existing in the cytoplasm break the esters links, restoring calcein natural form. For esterases to have a normal activity, cells must be viable, therefore, the greater is the fluorescence intensity greater is the number viable cells [35]. The procedure was adapted from Pedrosa and Soares-da-Silva (2002) [36]. Cells cultured in 96 well plates were incubated with 6OHDA $(100 \mu \mathrm{M})$ and seaweeds extracts that exhibited protective activities $(1 \mathrm{mg} / \mathrm{mL})$ during $24 \mathrm{~h}$. The solutions were previously prepared in culture medium without FBS and sterile filtered $(0.2 \mu \mathrm{m})$. Briefly, cells were washed twice with $200 \mu \mathrm{l}$ of Hank's buffer and loaded with $100 \mu \mathrm{l}$ of calcein $(2 \mu \mathrm{M})$. The 96 well plates were incubated at room temperature protected from light for $30 \mathrm{~min}$ and the fluorescence intensity of eight independent experiments were measured by a microplate reader (Biotec, Synergy H1 Hybrid Reader) at wavelengths of $490 \mathrm{~nm}$ (excitation) and $520 \mathrm{~nm}$ (emission) scanning all of each well surface. The results were expressed in percentage of control of the fluorescence scan read in eight independent wells. After the reader the cells were washed again with $200 \mu$ l Hank's buffer and finally was added $100 \mu \mathrm{l}$ of Hank's buffer to each situation. The effects were observed in a fluorescence inverted microscope (ZEISS Axio, VERT. A1, equipped with a AxioCam MRC-ZEISS camera, München, Germany). The images presented are representative of one well center-point of each situation tested.

\section{Quantification of hydrogen peroxide $\left(\mathrm{H}_{2} \mathrm{O}_{2}\right)$ production}

Quantification of $\mathrm{H}_{2} \mathrm{O}_{2}$ was performed using the "Amplex ${ }^{\mathrm{m}}$ Red hydrogen peroxide Assay" Kit (Life Tecnologies, A22188, Camarillo, USA). The amplex red is a fluorophore that evidence a low basal fluorescence which reacts in with $\mathrm{H}_{2} \mathrm{O}_{2}$ in a 1:1 ratio. This reaction is initiated in the presence of horseradish peroxidase and successive reactions occur leading to the appearance of highly fluorescent product, designated resofurin [37]. $\mathrm{H}_{2} \mathrm{O}_{2}$ production was quantified in SH-SY5Y cells after $12 \mathrm{~h}$ of treatment with 6-OHDA $(100 \mu \mathrm{M})$ in the absence or presence of seaweeds extracts $(1 \mathrm{mg} / \mathrm{mL})$. The variation of $\mathrm{H}_{2} \mathrm{O}_{2}$ production was accompanied in realtime along $60 \mathrm{~min}$ at room temperature. The fluorescence intensity was measured at wavelengths of $590 \mathrm{~nm}$ 
(excitation) and $530 \mathrm{~nm}$ (emission). The levels of $\mathrm{H}_{2} \mathrm{O}_{2}$ were calculated by the slope of the linear phase of fluorescence curve and the results were expressed in percentage of control.

\section{Mitochondrial membrane potential (MMP)}

MMP was determined using the fluorescent probe, JC-1 (Molecular Probes, T3168, Eugene, Oregon, USA). SHSY5Y cells were treated with 6-OHDA $(100 \mu \mathrm{M}), 3$ and $6 \mathrm{~h}$, in the absence or presence of seaweeds extracts $(1 \mathrm{mg} / \mathrm{mL})$. After this period, the culture medium was removed and the cells were washed with Hank's buffer and incubated $15 \mathrm{~min}$ at $37{ }^{\circ} \mathrm{C}$ with $\mathrm{JC}-1(3 \mu \mathrm{M})$. JC-1 probe was then removed and cells washed with Hank's buffer. The formation of JC-1 aggregates (490 nm of excitation and $590 \mathrm{~nm}$ of emission) and the monomeric form of JC-1 (490 $\mathrm{nm}$ of excitation and $530 \mathrm{~nm}$ of emission) was accompanied simultaneously in the plate reader during $30 \mathrm{~min}$. Results were expressed as the ratio of the monomers/aggregates of JC-1 in percentage of control.

\section{Caspase-3 activity}

Caspase-3 activity was assessed using "Caspase Assay kit” (Sigma, Casp3f, Saint Louis, USA). Cells were cultured in 6-well plates and treated with 6-OHDA $(100 \mu \mathrm{M}) 6 \mathrm{~h}$ in the presence or absence of seaweeds extracts $(1 \mathrm{mg} / \mathrm{mL})$. After this period the culture medium was removed, the cells were washed twice with Hank's buffer and collected by centrifugation $(8000 \mathrm{rpm}$, $10 \mathrm{~min}, 4^{\circ} \mathrm{C}$ ). The pellets were resuspended in $100 \mu \mathrm{L}$ of lysis buffer and incubated $20 \mathrm{~min}$ on ice. In order to separate the content of intracellular cytoplasmic organelles and cells membranes, centrifugation took place at $14000 \mathrm{rpm}$ during $20 \mathrm{~min}$ at $4{ }^{\circ} \mathrm{C}$. Thereafter, $5 \mu \mathrm{L}$ of the obtained supernatant was place in to a 96-well plate where it was added $200 \mu \mathrm{L}$ of a substrate solution which was prepared following the manufacturer's instructions. In this assay, the Caspase- 3 activity is accessed by measuring the fluorescence released by the fluorophore rhodamine 110 . When attached to the amino acid sequence, this fluorophore have a basal fluorescence, however, when detached from the amino acid sequence, rhodamine 110 is highly fluorescent. Caspase-3 is specific for cleaving the rhodamine-aminoacid solution (substrate) resulting in the fluorescent form of rhodamine 110, the product. This reaction was followed at wavelengths of $496 \mathrm{~nm}$ (excitation) and $520 \mathrm{~nm}$ (emission) along $60 \mathrm{~min}$ at room temperature. Caspase- 3 activity was calculated by the slope of the linear phase of the fluorescence resulting from the rhodamine $110 \mathrm{accu}$ mulation and expressed in arbitrary fluorescence units per mg protein per minute ( $\Delta$ fluorescence (u.a)/mg of protein/min).

\section{Statistical analysis}

One-way analysis of variance (ANOVA) with Dunnett's multiple comparison of group means were employed to determine significant differences relatively to the control treatment [38]. All other post-hoc analyses were accessed through Tukey test. All data were checked for normality and homoscedasticity. Comparisons concerning variables, which did not meet variance or distributional assumptions, were carried out with Kruskal-Wallis non-parametric tests [38]. Where applicable, results are presented as mean \pm standard error of the mean (SEM). Differences were considered statistically significant at level of 0.05 (that is, $p<0.05$ ). All calculations were performed using IBM SPSS Statistics 21 (IBM Corporation, Armonk, NY, USA) and GraphPad v5.1 (Graphpad Software, Inc. La Jolla, CA, USA). The determination of $\mathrm{IC}_{50}$ was calculated by the analysis of non-linear regression using GraphPad Prism software with the eq. $\mathrm{Y}=100 /\left(1+10^{(\mathrm{X}-\operatorname{LogIC50})}\right)$ equation.

\section{Results}

Neurotoxic effects induced by 6-OHDA on SH-SY5Y cells SH-SY5Y cells were exposed to different concentrations of 6-OHDA (10-1000 $\mu \mathrm{M})$ during $24 \mathrm{~h}$. As can be observed in the Fig. 1, 6-OHDA induced a concentrationdependent effect on the viability of SH-SY5Y cells with an $\mathrm{IC}_{50}$ of $116.7 \mu \mathrm{M}$ (93.25-146.6). The highest neurotoxicity effect was obtained at $300 \mu \mathrm{M}$ and $1000 \mu \mathrm{M}$ with a cell viability reduction of more than $80 \%$. For the concentrations (100-1000 $\mu \mathrm{M})$ that exhibited neurotoxicity on SH-SY5Y cells was defined the time-course effects after 6, 12, 24 and $48 \mathrm{~h}$. All the tested concentrations of 6-OHDA showed a time-dependent effect (Fig. 1b).

\section{Neuroprotective effect of seaweeds on SH-SY5Y cells exposed to 6-OHDA}

The exposition of SH-SY5Y cells to 6-OHDA (100 $\mu \mathrm{M})$ led to a reduction of about $35 \%(67.40 \pm 3.56$ of viable cells) of cell's viability. However, when 6-OHDA was incubated with seaweeds $(1 \mathrm{mg} / \mathrm{mL})$, all extracts, with exception for the dichloromethane extract of S. muticum exhibited capacity to totally blunt the toxicity induced by 6-OHDA after $24 \mathrm{~h}$ of incubation (Fig. 2). On the other hand, the dichloromethane extract of $S$. muticum $(84.73 \pm 2.73 \%$ of viable cells) did not showed statistically significant differences when compared to 6-OHDA situation (ANOVA, $p>0.05$ ). These results were confirmed both by the Calcein -AM assay that showed that all extracts protected cells from the toxic effects induced by 6-OHDA (Fig. 3a) and by the representative fluorescent images of 6-OHDA treatment in the presence or in the absence of the seaweeds extracts (Fig. 3b). 

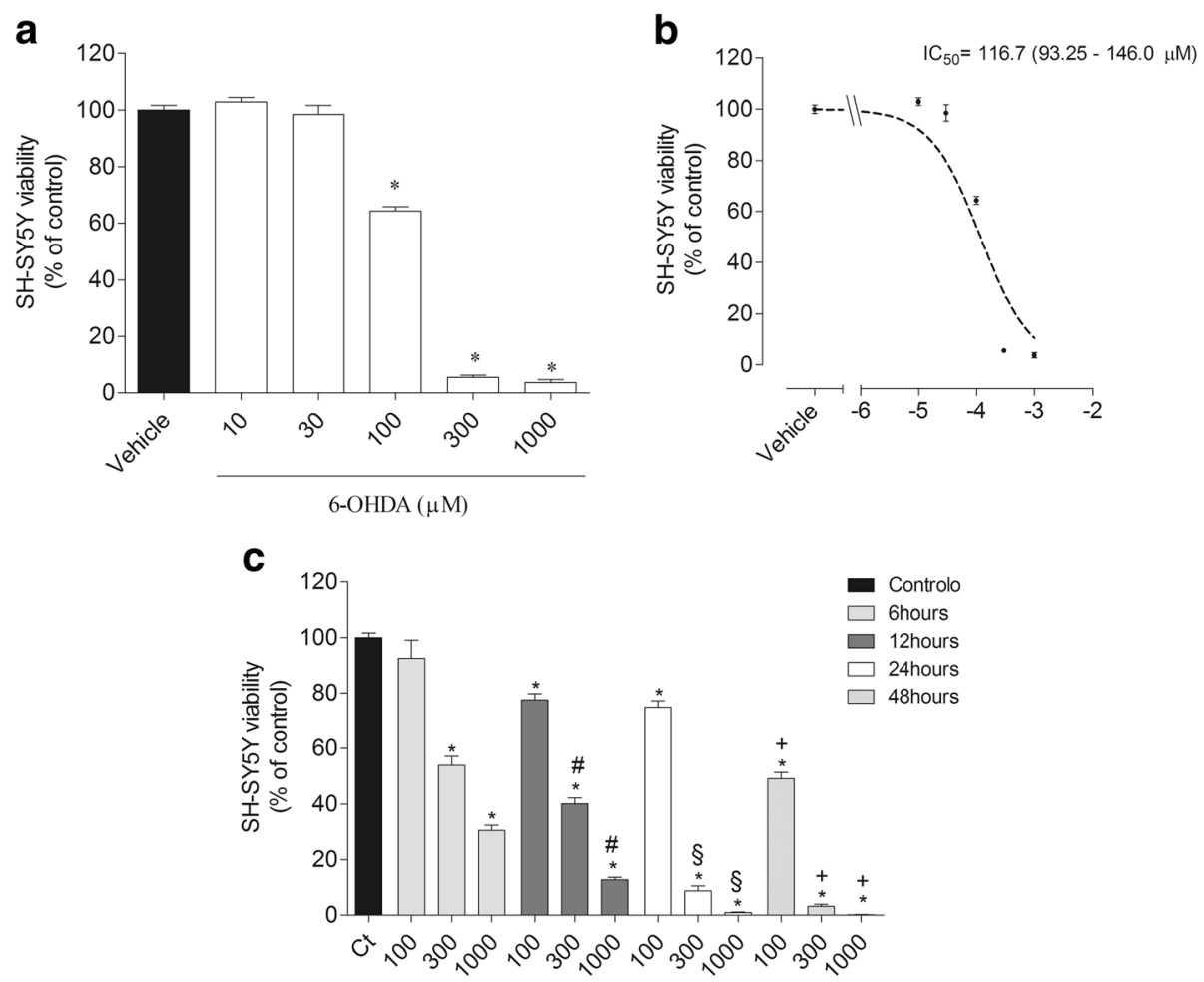

6 - OHDA ( $\mu \mathrm{M})$

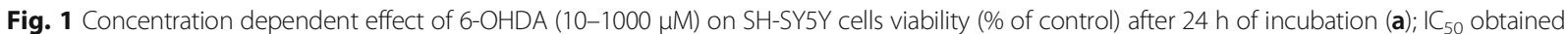
from different concentrations of 6-OHDA (100-1000 $\mu \mathrm{M})(\mathbf{b})$; Effect of 6 - OHDA (100-1000 $\mu \mathrm{M})$ on SH-SY5Y cells viability (\% of control) after different times of incubation $6,12,24$ and $48 \mathrm{~h}$ (c). Results were obtained by the MTT method. Values are mean \pm SEM $(n=16)$. Symbols represent statistically significant differences ( $p<0.05$, ANOVA, Tukey test) when compared to: *vehicle; ${ }^{*} 6 \mathrm{~h} ;{ }^{\S} 12 \mathrm{~h} ;{ }^{+} 24 \mathrm{~h}$

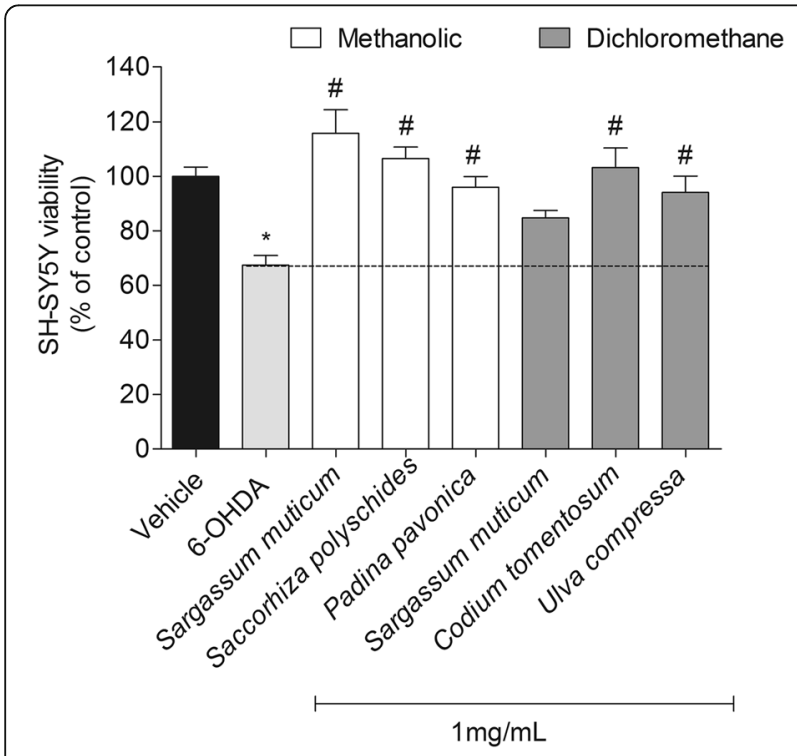

Fig. 2 Neuroprotective effects of seaweeds extracts $(1 \mathrm{mg} / \mathrm{mL})$ on SH-SY5Y cells exposed to 6-OHDA (100 $\mu$ M). Determination of cell viability by the MTT method (\% control) after $24 \mathrm{~h}$ of incubation. Values are mean \pm SEM $(n=16)$. Symbols represent statistically significant differences ( $p<0.05$, ANOVA, Dunett's test) when compared to: *vehicle. " to 6-OHDA

\section{Cellular mechanisms associated to the neurotoxicity induced by 6-OHDA on SH-SY5Y cells in the presence or absence of seaweeds extracts \\ Production of $\mathrm{H}_{2} \mathrm{O}_{2}$}

In order to understand if the neurotoxicity induced by 6 OHDA and the neuroprotection evidenced by seaweeds extracts on cell viability of SH-SY5Y was associated with oxidative stress, the $\mathrm{H}_{2} \mathrm{O}_{2}$ production was quantified.

The exposition of SH-SY5Y cells to 6-OHDA $(100 \mu \mathrm{M})$ led to an increase of more than twice the levels of $\mathrm{H}_{2} \mathrm{O}_{2}$ comparing with vehicle (Fig. 4). Moreover, when the cells were incubated with 6-OHDA in the presence of seaweeds extracts $(1 \mathrm{mg} / \mathrm{mL})$ the levels of $\mathrm{H}_{2} \mathrm{O}_{2}$ decreased partially or totally when compared with 6-OHDA. The highest decrease was carried out by the dichloromethane extract of Codium tomentosum $(54.07 \pm 6.66 \%$ of control) when compared with 6-OHDA (214.26 $\pm 8.46 \%$ of control) and vehicle $(100.00 \pm 9.48 \%$ of control). Within the extracts with neuroprotective potential, Ulva compressa was the only extract that did not exhibited capacity to decrease the $\mathrm{H}_{2} \mathrm{O}_{2}$ production induced by 6OHDA. 


\section{b}
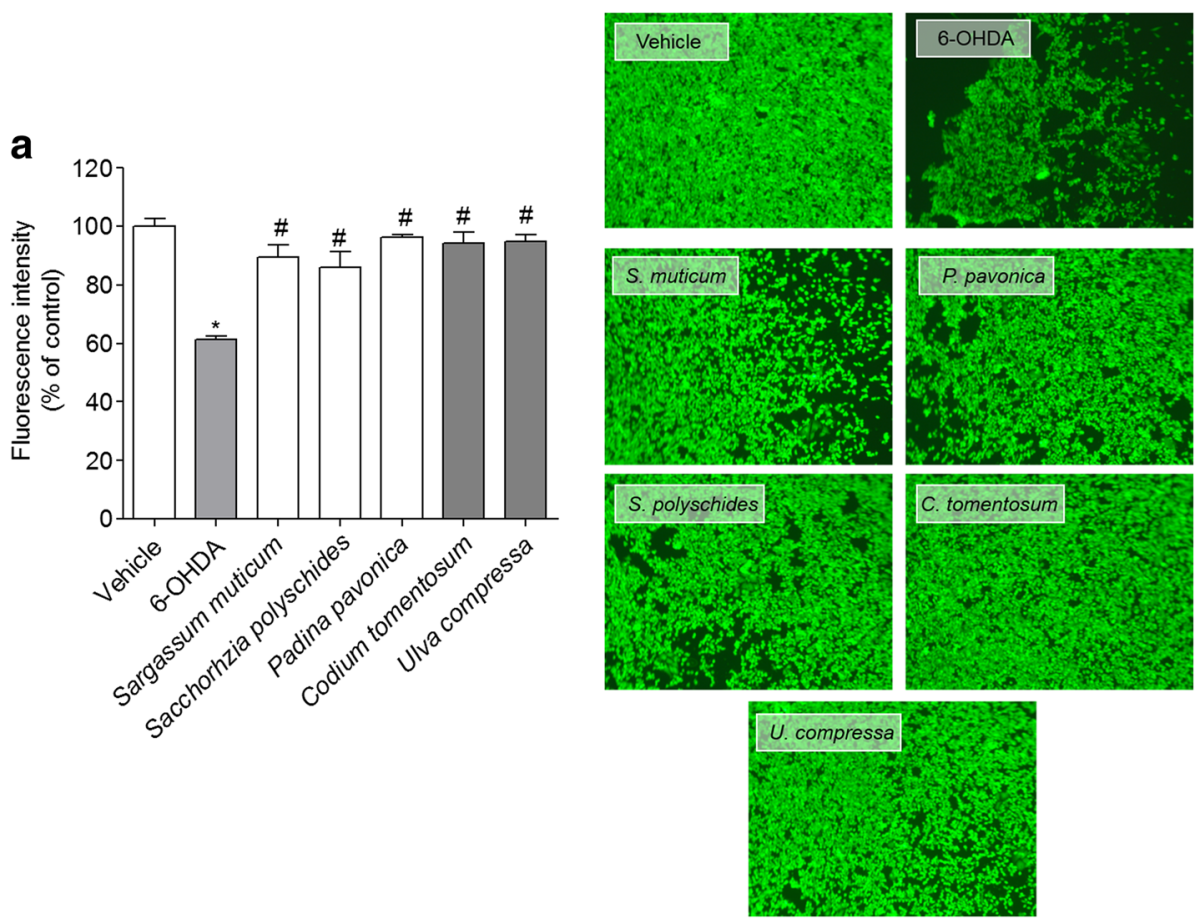

Fig. 3 Neuroprotective effects of seaweeds extracts (1 mg/mL) on SH-SY5Y cells exposed to 6-OHDA (100 $\mu \mathrm{M})$ revealed by Calcein-AM method a) Read of fluorescence (\% control) after $24 \mathrm{~h}$ of incubation. Values are mean $\pm \operatorname{SEM}(n=8)$. Symbols represent statistically significant differences ( $p<0.05$, ANOVA, Dunett's test) when compared to: * vehicle. " to 6-OHDA. b Observation by fluorescence microscopy of the effects induced by 6-OHDA and seaweeds extracts. The images are representative of each treatment done and correspond to the center-point of one well. Methanolic extract: Sargassum muticum, Padina pavonica and Saccorhiza polyschides; Dichloromethane extract: Codium tomentosum and Ulva compressa

\section{Mitochondrial membrane potential (MMP)}

The incubation of SH-SY5Y cells with 6-OHDA $(100 \mu \mathrm{M}-3 \mathrm{~h})$ induced a strong depolarization of the MMP when compared with vehicle (Fig. 5a). Moreover, this effect was also time-dependent, since after $6 \mathrm{~h}$ of incubation with 6-OHDA the depolarization increased twice when compared with the $3 \mathrm{~h}$ exposure. During the treatment with seaweeds $(3 \mathrm{~h})$ it was possible to observe a noticeable preventive effect of $S$. muticum, C. tomentosum and $U$. compressa extracts in the depolarization induced by 6-OHDA. On the other hand, the extracts of $S$. polyschides and $P$. pavonica only prevented the effects induced by 6-OHDA after $6 \mathrm{~h}$ of incubation (Fig. 5b).

\section{Caspase-3 activity}

In order to understand if the cell death promoted by 6 OHDA is mediated by apoptosis, it was decided to study the Caspase- 3 activity, since it is an important biomarker in this process. The results showed a noticeable increase of Caspase-3 activity when SH-SY5Y cells were treated with $100 \mu \mathrm{M}$ of 6 -OHDA $(1536.72 \pm 154.76 \%$ of control) comparing with vehicle $(100 \pm 33.24 \%$ of control). Furthermore, when cells were incubated with 6-OHDA and seaweeds extracts $(1 \mathrm{mg} / \mathrm{mL})$ it was possible to detect a reduction of Caspase-3 activity when compared with 6-OHDA. The extracts from C. tomentosum, S. polyschides, $P$. pavonica and $U$. compressa completely inhibited the stimulation of Caspase- 3 by 6-OHDA. S. muticum also revealed this capacity but the effects were not so marked (Fig. 6).

\section{Discussion}

PD is a neurodegenerative disease of the central nervous system characterized by a progressive loss of dopaminergic neurons that underlie the characteristic motor symptoms. This disease still doesn't have an affective cure and therefore exists an increasing interest in the development of more selective and effective therapeutic agents in order to prevent or slow down the neurodegeneration progression [15, 18, 25, 26, 39]. Although the causes PD pathogenesis remains incomplete, considerable evidences from human and animal studies have suggested that mechanisms such as oxidative stress, mitochondrial and lysosomal dysfunctions, neuroinflammatory processes, and the formation of pathologic inclusions contributes to neuronal death in $\mathrm{PD}[4,5]$. In line with this, the present study was designed to evaluate the 


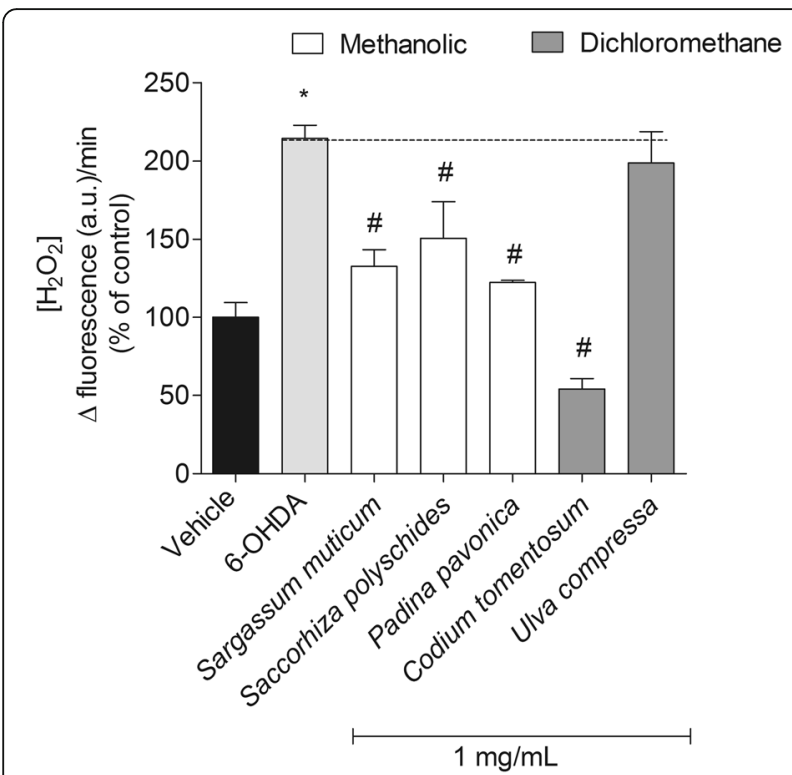

Fig. 4 Levels of hydrogen peroxide $\left(\mathrm{H}_{2} \mathrm{O}_{2}\right)$ produced by SH-SY5Y cells after $12 \mathrm{~h}$ of incubation with 6-OHDA (100 $\mathrm{MM})$ in presence or absence of seaweeds extracts ( $1 \mathrm{mg} / \mathrm{mL}$ ). $\mathrm{H}_{2} \mathrm{O}_{2}$ was quantified fluorimetrically using the "TMM Amplex red hydrogen peroxide assay" kit. Symbols represent statistically significant differences $(p<0.05$, ANOVA, Dunett's test) when compared to: ${ }^{*}$ vehicle. ${ }^{\#}$ to 6-OHDA

protective effects of seaweeds on SH-SY5Y cells exposed to the toxicity of 6-OHDA.

The neurotoxicity induced by 6-OHDA on SH-SY5Y cells has been previously reported by different authors, consequently, this model has been widely used to mimic experimental models of PD [5, 6, 11, 40]. According to previous studies, once inside the neurons, 6-OHDA accumulates and undergoes a non-enzymatic autooxidation, promoting the reactive oxygen species formation (e.g. superoxide radical, hydrogen peroxide, quinones and hydroxyl radicals) and inhibit the mitochondrial complexes I and IV, causing adenosine triphosphate (ATP) depletion. All these supports the hypothesis that oxidative stress and mitochondrial dysfunction may be responsible for the cell death $[5,41,42]$. Moreover, these two events are described as being entirely related, since the occurrence of mitochondrial dysfunction can lead to ATP depletion, inducing irreversible effects on the cellular processes, leading to the formation of free radicals. Consequently, the loss of mitochondrial transmembrane potential can result in the rupture of the outer mitochondrial membrane and in the release of pro-apoptotic proteins from the nucleus leading to cell death through activation of the intrinsic apoptosis pathway [43-45]. Our results are entirely according with these facts, since the observed reduction on SH-SY5Y cells viability was accompanied by an increase of $\mathrm{H}_{2} \mathrm{O}_{2}$ production, depolarization of mitochondrial membrane potential and an increase of Caspase-3
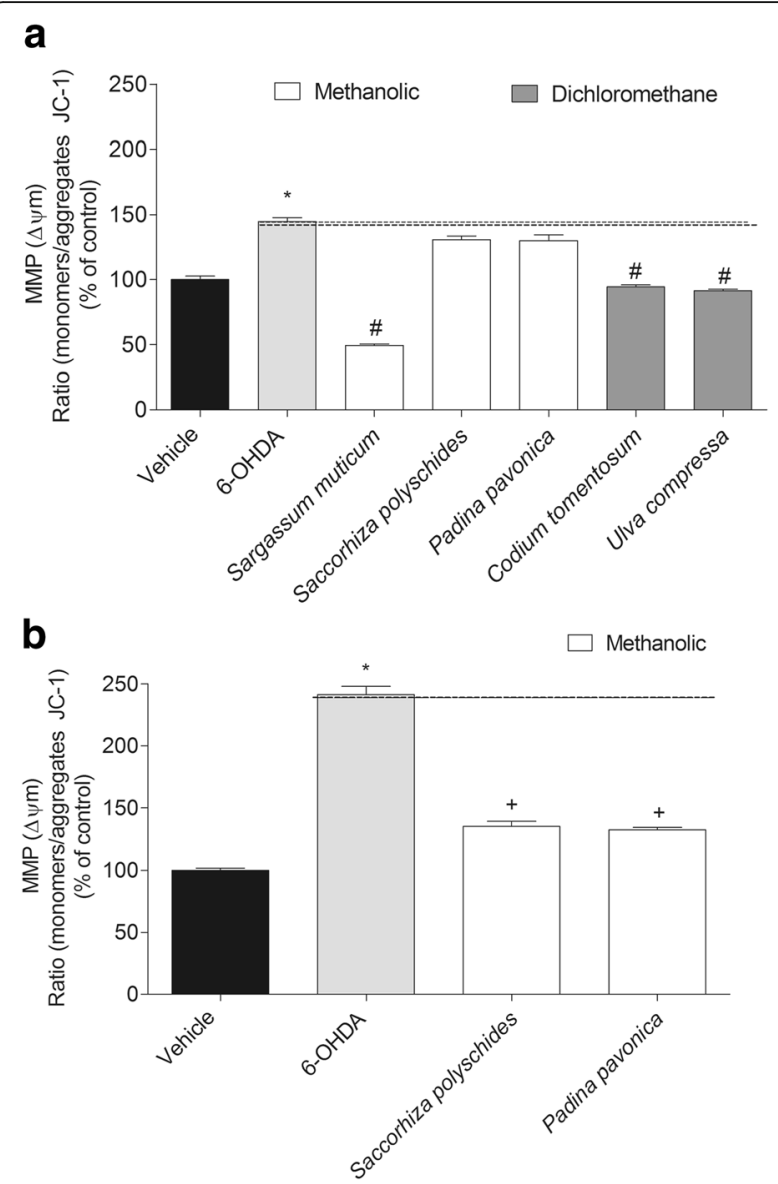

Fig. 5 6-OHDA (100 $\mu \mathrm{M})$ effects in the presence or absence of seaweeds extracts $(1 \mathrm{mg} / \mathrm{mL})$ in mitochondrial membrane potential of SH-SY5Y cells after $3 \mathrm{~h}(\mathbf{a})$ and $6 \mathrm{~h}(\mathbf{b})$ of incubation. The results were obtained by the ratio between the monomers/aggregates of $J C-1$. The values in each column represent the mean \pm standard error of the mean (SEM) of 3 or 4 independent experiments. Symbols represent statistically significant differences $(p<0.05$, ANOVA, Dunett's test) when compared to: " vehicle. ${ }^{\#}$ to 6-OHDA

activity, suggesting that cell death induced by the 6OHDA treatment was mediated by these mechanisms. Moreover, our results are supported by Esmaeili-Mahani and co-workers [11] that observed a significant increase of intracellular ROS, activated Caspase $3, \mathrm{Bax} / \mathrm{Bcl}-2$ ratio, cytochrome $\mathrm{c}$ as well as DNA fragmentation in 6-OHDAtreated cells. For other side, when SH-SY5Y cells were treatment with 6-OHDA in the presence of seaweeds extracts was possible to see a marked increase of cell's viability. The data obtained suggests that the protective effects induced by seaweeds extracts result in a reduction of oxidative stress condition $\left(\mathrm{H}_{2} \mathrm{O}_{2}\right.$ production pathway) and an anti-apoptotic effect (mitochondrial protection and decrease of Caspase- 3 activity). Several experiments revealed that therapies including the intake of antioxidants display a protective effect on the degeneration of dopaminergic neurons suggesting that pharmacological targeting of the 


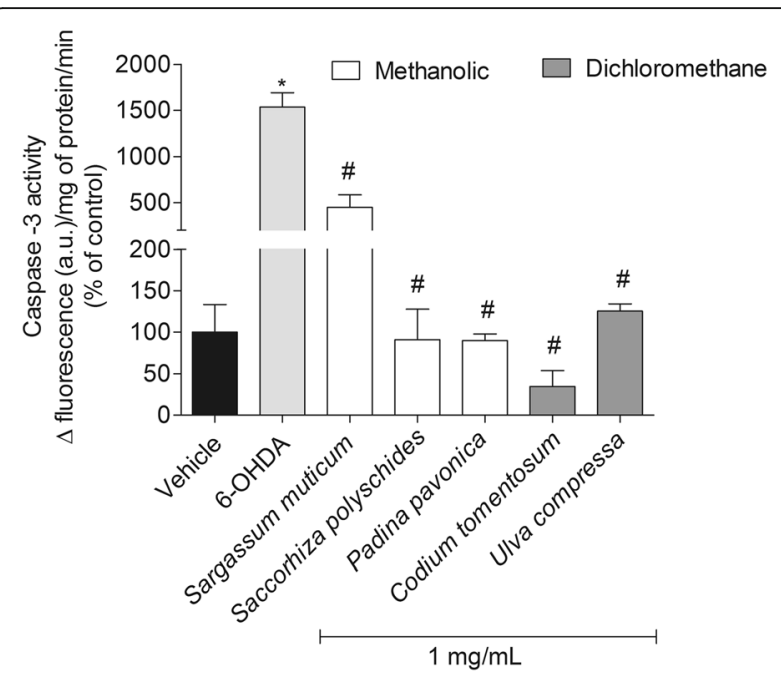

Fig. 6 6-OHDA $(100 \mu \mathrm{M})$ effects in the presence or absence of seaweeds extracts ( $1 \mathrm{mg} / \mathrm{mL}$ ) on Caspase-3 activity of SH-SY5Y cells after $6 \mathrm{~h}$ of treatment. The activity was quantified by the slope of the linear phase accumulation of Rhodamine 110 (between 20 and $40 \mathrm{~min}$ ). The results are presented in arbitrary units of fluorescence per mg protein. The values in each column represent the mean \pm standard error of the mean (SEM) from 3 to 4 experiments. Symbols represent statistically significant differences $(p<0.05$, ANOVA, Dunett's test) when compared to: "vehicle. " to 6-OHDA

antioxidant machinery may have therapeutic value $[6,16-19,46]$. According with this, the neuroprotective effects of seaweeds can be mediated by the antioxidants molecules present in their extracts, since these were selected by having a high antioxidant capacity. Among marine organisms, seaweeds are an interesting source of new compounds with antioxidant activity and neuroprotective potential. They are subjected to periods of immersion and emersion being exposed to rapid variations of light, UV rays and different oxygen $\left(\mathrm{O}_{2}\right)$ and carbon dioxide $\left(\mathrm{CO}_{2}\right)$ concentrations, factors that are related with oxidizing effects. This situation stimulates the production of antioxidant defenses, such as the production of phenolic compounds [47, 48]. The protective effects exhibited by seaweeds belonging to the brown algae group (S. muticum, S. polyschides and P. pavonica) can be associated with the presence of phlorotannins (molecules produced exclusively by brown algae). Phlorotannins, are phenolic compounds with a strong antioxidant capability $[49,50]$ suggesting that these may be responsible by the observed reduction of $\mathrm{H}_{2} \mathrm{O}_{2}$ levels. In fact, seaweeds have revealed to produce a high diversity of compounds with antioxidant activity. Codium tomentosum, a green seaweed also revealed an oxidative-stress protective effect. Celikler and co-workers [51] demonstrated that C. tomentosum extracts have strong anti-oxidative activity which can explain the highest reduction of the $\mathrm{H}_{2} \mathrm{O}_{2}$ production observed in presence of this extract.
On the other hand, several studies reported that the neuroprotection effect of different compounds is normally mediated by the prevention of mitochondrial depolarization, the reduction of ROS levels and the inhibition of apoptotic process leading to an increase of cell's viability $[11,52,53]$. In our study was also possible to observe these effects, since the increase of cell's viability by seaweeds extracts seems to be mediated by the reduction of $\mathrm{H}_{2} \mathrm{O}_{2}$ levels, the protection of mitochondrial membrane potential and the inhibition of Caspase- 3 activity. According to our results, several other compounds of natural origin such as, astaxanthin (obtained from Haematococcus pluvialis) and 11-dehydrosinulariolide (obtained from the coral Sinularia flexibilis) have exhibited anti-apoptotic effects, notably by decreasing the Caspase-3 expression and cytochrome $\mathrm{c}$ in SH-SY5Y cells when treated 6-OHDA. Similarly, the neuropeptide orexin-A, exhibit anti-apoptotic effects by the same mechanisms [6, 11, 31]. In line with our findings, Jhamandas and co-workers [54] showed neuroprotective activity of a fucoidan sulfated polysaccharide, isolated from the brown seaweed Fucus vesiculosus, through the ability to protect neuronal death in rats treated with A $\beta 1-42$ the by inhibition of Caspase- 3 in an Alzheimer's disease model. Although not directly related to the disease addressed in this work, the effects induced by fucoidan demonstrate the potential of seaweeds as source of new neuroprotective molecules.

\section{Conclusions}

In conclusion, the seaweeds extracts with high antioxidant capacity analyzed in this study showed to be a promising source of new compounds with neuroprotective potential revealing capacity to increase the SH-SY5Y cell's viability by the reduction of $\mathrm{H}_{2} \mathrm{O}_{2}$ levels, the protection of mitochondrial membrane potential and the inhibition of Caspase-3 activity, reducing the neurotoxic effects induced by 6-OHDA.

\section{Abbreviations}

-OH: Hydroxyl radical; 6-OHDA: 6- Hydroxidopamine; ANOVA: Analysis of variance; ATP: Adenosine trisphosphate; C. tomentosum: Codium tomentosum; $\mathrm{CO}_{2}$ : Carbon dioxide; DMEM: Dulbecco's modified Eagle medium; FBS: Fetal bovine serum; $\mathrm{H}_{2} \mathrm{O}_{2}$ : Hydrogen peroxide; JC-1: 5,5',6,6'-tetrachloro-1,1',3,3'tetraethylbenzimi- dazolylcarbocyanine iodide; MTT: 3-(4,5-dimethylthiazol2yl)-2,5-diphenltetrazolium bromide; $\mathrm{O}_{2}$ : Oxigen; $\mathrm{O}_{2} \bullet^{-}$: Superoxide radical; $P$. pavonica: Padina pavonica; PD: Parkinson Disease; ROS: Reactive oxygen species; S. muticum: Sargassum muticum; S. pPolyschides: Saccorhiza polyschides; SH-SY5Y: Human neuroblastoma cell line; SNpc: Substancia nigra par compact; U. compressa: Ulva compressa

\section{Acknowledgments}

This study had the support of the Fundação para a Ciência e a Tecnologia (FCT) Strategic Project UID/MAR/04292/2013 granted to MARE. Joana Silva, Celso Alves and Susete Pinteus were financial supported by a from FCTFundação para a Ciência e Tecnologia grants SFRH/BD/103255/2014, SFRH/ BD/977641/2013 and SFRH/BD/96203/2013, respectively. 


\section{Funding}

Authors would like to acknowledge the financial support of the Portuguese Foundation for Science and Technology (FCT) through Strategic Project UID/MAR/04292/2013 granted to MARE - Marine and Environmental Sciences Centre, Red2Discovery Project (PTDC/MAR-BIO/ 6149/2014), co-financed by COMPETE (POCI-01-0145-FEDER-016791). The authors also wish to acknowledge the Integrated Programme of SR\&TD "Smart Valorization of Endogenous Marine Biological Resources Under a Changing Climate" (reference Centro-01-0145-FEDER-000018), co-funded by Centro 2020 program, Portugal 2020, European Union, through the European Regional Development Fund and SAICTPAC/0019/2015 LISBOA-01-0145-FEDER-016405 Oncologia de Precisão: Terapias e Tecnologias Inovadoras (POINT4PAC). Joana Silva, Celso Alves and Susete Pinteus are financial supported by a grant from FCT (SFRH/BD/103255/ 2014, SFRH/BD/97764/2013 and SFRH/BD/96203/2013 respectively).

\section{Availability of data and materials}

All the experimental design, laboratorial procedures and raw data are present in the lab book of Joana Silva author, as well in the lab laptop that could be accessed in the Cetemares building, Peniche, Portugal. All the data generated and analyzed in this study are included in this published article. Not applicable since all the data supporting the results reported are in this manuscript

\section{Author's contributions}

The author JS did the main experiments (cytotoxicity, neuroprotective assay, mechanisms the apoptotic, mitochondrial membrane potential and $\mathrm{H}_{2} \mathrm{O}_{2}$ production and drafted the manuscript). CA and SP have been involved in the cytotoxicity and neuroprotective assay. SM coordinated the experimental design and analyzed the data. RP designed and coordinated the cytotoxicity, neuroprotective assay, mechanisms the apoptotic, mitochondrial membrane potential and $\mathrm{H}_{2} \mathrm{O}_{2}$ production and conceived the study. All authors read and approved the final manuscript and are accountable for the integrity of this manuscript.

\section{Ethics approval and consent to participate}

Not applicable.

\section{Consent for publication}

Not applicable.

\section{Competing interest}

The authors declare that they have no competing interest.

\section{Publisher's Note}

Springer Nature remains neutral with regard to jurisdictional claims in published maps and institutional affiliations.

\section{Author details}

'MARE - Marine and Environmental Sciences Centre, ESTM, Instituto Politécnico de Leiria, 2520-641 Peniche, Portugal. Faculty of Veterinary, University of Santiago de Compostela, 27002 Lugo, Spain.

Received: 3 March 2017 Accepted: 17 January 2018 Published online: 14 February 2018

\section{References}

1. Skovronsky DM, Lee VM-Y, Trojanowski JQ. Neurodegenerative diseases: new concepts of pathogenesis and their therapeutic implications. Annu Rev Pathol Mech Dis. 2006:1:151-70.

2. García-Ayllón M-S, Cauli O, Silveyra M-X, Rodrigo R, Candela A, Compañ A, Jover R, Pérez-Mateo M, Martínez S, Felipo V. Brain cholinergic impairment in liver failure. Brain. 2008;131:2946-56.

3. Bernheimer H, Birkmayer W, Hornykiewicz O, Jellinger $K$, Seitelberger F. Brain dopamine and the syndromes of Parkinson and Huntington clinical, morphological and neurochemical correlations. J Neurol Sci. 1973;20:415-55.

4. Tolleson CM, Fang JY. Advances in the mechanisms of Parkinson's disease. Discov Medicine. 2013;15:61-6.

5. Cunha MP, Martín-de-Saavedra MD, Romero A, Parada E, Egea J, del Barrio L, Rodrigues ALS, López MG. Protective effect of creatine against 6- hydroxydopamine-induced cell death in human neuroblastoma SH-SY5Y cells: involvement of intracellular signaling pathways. Neuroscience. 2013;238:185-94.

6. Ikeda Y, Tsuji S, Satoh A, Ishikura M, Shirasawa T, Shimizu T. Protective effects of astaxanthin on 6-hydroxydopamine-induced apoptosis in human neuroblastoma SH-SY5Y cells. J Neurochem. 2008;107:1730-40.

7. Duty S, Jenner P. Animal models of Parkinson's disease: a source of novel treatments and clues to the cause of the disease. Br J Pharmacol. 2011;164: 1357-91.

8. Tieu K. A guide to neurotoxic animal models of Parkinson's disease. Cold Spring Harb. Perspect. Med. 2011;1:a009316.

9. Perier C, Vila M. Mitochondrial biology and Parkinson's disease. Cold Spring Harb Perspect Med. 2012;2:a009332.

10. Dias $\mathrm{V}$, Junn $\mathrm{E}$, Mouradian MM. The role of oxidative stress in Parkinson's disease. J Park Dis. 2013;3:461-91.

11. Esmaeili-Mahani S, Vazifekhah S, Pasban-Aliabadi H, Abbasnejad M, Sheibani $V$. Protective effect of orexin-a on 6-hydroxydopamine-induced neurotoxicity in SH-SY5Y human dopaminergic neuroblastoma cells. Neurochem Int. 2013;63:719-25.

12. Segal RA, Greenberg ME. Intracellular signaling pathways activated by neuropathic factors. Annu Rev Neurosci. 1996;19:463-89.

13. Lotharius J, Dugan LL, O'malley KL. Distinct mechanisms underlie neurotoxin-mediated cell death in cultured dopaminergic neurons. J Neurosci. 1999:19:1284-93.

14. Xie HR, Hu LS, Li GY. SH-SY5Y human neuroblastoma cell line: in vitro cell model of dopaminergic neurons in Parkinson's disease. Chin Med J. 2010; 123:1086-92.

15. Lou $H$, Jing $X$, Wei $X$, Shi $H$, Ren D, Zhang X. Naringenin protects against 6OHDA-induced neurotoxicity via activation of the Nrf2/ARE signaling pathway. Neuropharmacology. 2014;79:380-8.

16. Tian L-L, Wang X-J, Sun Y-N, Li C-R, Xing Y-L, Zhao H-B, Duan M, Zhou Z, Wang S-Q. Salvianolic acid B, an antioxidant from salvia miltiorrhiza, prevents 6-hydroxydopamine induced apoptosis in SH-SY5Y cells. Int J Biochem Cell Biol. 2008;40:409-22.

17. Levites $Y$, Youdim MBH, Maor G, Mandel S. Attenuation of 6hydroxydopamine (6-OHDA)-induced nuclear factor-kappaB (NF-kB) activation and cell death by tea extracts in neuronal cultures. Biochem Pharmacol. 2002;63:21-9.

18. Mansouri MT, Farbood Y, Sameri MJ, Sarkaki A, Naghizadeh B, Rafeirad M. Neuroprotective effects of oral gallic acid against oxidative stress induced by 6-hydroxydopamine in rats. Food Chem. 2013;138:1028-33.

19. Mandel S, Youdim MBH. Catechin polyphenols: neurodegeneration and neuroprotection in neurodegenerative diseases. Free Radic Biol Med. 2004; 37:304-17.

20. de Rijk MC, Breteler MB, den Breeijen $\mathrm{JH}$, et al. Dietary antioxidants and parkinson disease: the rotterdam study. Arch Neurol. 1997;54:762-5.

21. Etminan M, Gill SS, Samii A. Intake of vitamin E, vitamin C, and carotenoids and the risk of Parkinson's disease: a meta-analysis. Lancet Neurol. 2005:4:362-5.

22. Gao X, Chen H, Fung TT, Logroscino G, Schwarzschild MA, Hu FB, Ascherio A. Prospective study of dietary pattern and risk of Parkinson disease. Am J Clin Nutr. 2007;86:1486-94

23. Okubo H, Miyake Y, Sasaki S, Murakami K, Tanaka K, Fukushima W, Kiyohara C, Tsuboi Y, Yamada T, Oeda T, et al. Dietary patterns and risk of Parkinson's disease: a case-control study in Japan. Eur J Neurol. 2012:19:681-8.

24. Miyake Y, Fukushima W, Tanaka K, Sasaki S, Kiyohara C, Tsuboi Y, Yamada T, Oeda T, Miki T, Kawamura N, et al. Dietary intake of antioxidant vitamins and risk of Parkinson's disease: a case-control study in Japan. Eur J Neurol. 2011;18:106-13.

25. Haefner B. Drugs from the deep: marine natural products as drug candidates. Drug Discov Today. 2003:8:536-44.

26. Murray PM, Moane S, Collins C, Beletskaya T, Thomas OP, Duarte AWF, Nobre FS, Owoyemi IO, Pagnocca FC, Sette LD, et al. Sustainable production of biologically active molecules of marine based origin. New Biotechnol. 2013;30:839-50

27. Horta A, Pinteus S, Alves C, Fino N, Silva J, Fernandez S, Rodrigues A, Pedrosa R. Antioxidant and antimicrobial potential of the Bifurcaria bifurcata epiphytic bacteria. Mar. Drugs. 2014;12:1676-89.

28. Pangestuti R, Kim S-K. Neuroprotective effects of marine algae. Mar Drugs, 2011;9:803-18.

29. Ahn B, Moon H, Kim H, Jung H, Choi J. Neuroprotective effect of edible brown alga Eisenia bicyclis on amyloid beta peptide-induced toxicity in PC12 cells. Arch Pharm Res. 2012;35:1989-98. 
30. Jin D-Q, Lim CS, Sung J-Y, Choi HG, Ha I, Han J-S. Ulva Conglobata, a marine algae, has neuroprotective and anti-inflammatory effects in murine hippocampal and microglial cells. Neurosci Lett. 2006;402:154-8.

31. Chen W-F, Chakraborty C, Sung C-S, Feng C-W, Jean Y-H, Lin Y-Y, Hung H-C, Huang T-Y, Huang S-Y, Su T-M, et al. Neuroprotection by marine-derived compound, 11-dehydrosinulariolide, in an in vitro Parkinson's model: a promising candidate for the treatment of Parkinson's disease. Naunyn Schmiedeberg's Arch Pharmacol. 2012;385:265-75.

32. Castel J, Lechn G. In vitro methods in pharmaceutical research. In: Academic Press (1st Eds). London; 1996. p. 467.

33. Rotter BA, Thompson BK, Clarkin S, Owen TC. Rapid colorimetric bioassay for screening of Fusarium mycotoxins. Nat Toxins. 1993;1:303-7.

34. Pinteus S, Silva J, Alves C, Horta A, Fino N, Inês Rodrigues A, Mendes S, Pedrosa R. Cytoprotective effect of seaweeds with high antioxidant activity from the Peniche coast (Portugal). Food Chem. 2016.

35. Hayes W, Kruger C. Hayes principles and methods of toxicology. In: Taylor \& Francis Group (6th Eds). Boca Raton; 2014. p. 824.

36. Pedrosa R, Soares-da-Silva P. Oxidative and non-oxidative mechanisms of neuronal cell death and apoptosis by L-3,4-dihydroxyphenylalanine (L-DOPA) and dopamine. Br J Pharmacol. 2002;137:10305-1313.

37. Mohanty J, Jaffe JS, Schulman ES, Raible DG. A highly sensitive fluorescent micro-assay of $\mathrm{H}_{2} \mathrm{O}_{2}$ release from activated human leukocytes using a dihydroxyphenoxazine derivative. J Immunol Methods. 1997;202:133-41.

38. Zar JH. Biostatistical analysis. NJ, USA: Prentice Hall: Upper Saddle River; 2010

39. Kopalli SR, Noh S-J, Koppula S, Suh Y-H. Methylparaben protects 6hydroxydopamine-induced neurotoxicity in SH-SY5Y cells and improved behavioral impairments in mouse model of Parkinson's disease. Neurotoxicology. 2013;34:25-32.

40. Tiong CX, Lu M, Bian J-S. Protective effect of hydrogen sulphide against 6OHDA-induced cell injury in SH-SY5Y cells involves PKC/PI3K/Akt pathway. Br J Pharmacol. 2010;161:467-80.

41. Bové J, Perier C. Neurotoxin-based models of Parkinson's disease. Neuroscience. 2012;211:51-76.

42. Glinka $Y$, Tipton $\mathrm{K}$, Youdim M. Nature of inhibition of mitochondrial respiratory complex I by 6-Hydroxydopamine. J Neurochem. 1996;66:2004-10.

43. Joza N, Susin SA, Daugas E, Stanford WL, Cho SK, Li CY, Sasaki T, Elia AJ, Cheng H-YM, Ravagnan L. Essential role of the mitochondrial apoptosisinducing factor in programmed cell death. Nature. 2001:410:549-54.

44. Beal MF. Energetics in the pathogenesis of neurodegenerative diseases. Trends Neurosci. 2000;23:298-304

45. Onyango IG. Mitochondrial dysfunction and oxidative stress in Parkinson's disease. Neurochem Res. 2008;33:589-97.

46. Kita T, Asanuma M, Miyazaki I, Takeshima M. Protective effects of Phytochemical antioxidants against neurotoxin-induced degeneration of Dopaminergic neurons. J Pharmacol Sci. 2014;124:313-9.

47. Zandi K, Tajbakhsh S, Nabipour I, Rastian Z, Yousefi F, Sharafian S, Sartavi K In vitro antitumor activity of Gracilaria corticata (a red alga) against Jurkat and molt-4 human cancer cell lines. Afr J Biotechnol. 2013;9:6787-90.

48. Ghasemzadeh A, Jaafar HZE, Rahmat A, Wahab PEM, Halim MRA. Effect of different light intensities on Total Phenolics and Flavonoids synthesis and anti-oxidant activities in young ginger varieties (Zingiber Officinale roscoe). Int J Mol Sci. 2010;11:3885-97.

49. Kang K, Park Y, Hwang HJ, Kim SH, Lee JG, Shin H-C. Antioxidative properties of brown algae polyphenolics and their perspectives as chemopreventive agents against vascular risk factors. Arch Pharm Res. 2003:26:286-93.

50. Dalle-Donne I, Rossi R, Colombo R, Giustarini D, Milzani A. Biomarkers of oxidative damage in human disease. Clin Chem. 2006:52:601-23.

51. Celikler S, Vatan O, Yildiz G, Bilaloglu R. Evaluation of anti-oxidative, genotoxic and antigenotoxic potency of Codium tomentosum Stackhouse ethanolic extract in human lymphocytes in vitro. Food Chem Toxicol. 2009; 47:796-801.

52. Kim DW, Ahan SH, Kim TY. Enhancement of arsenic trioxide (As2O3)mediated apoptosis using berberine in human neuroblastoma SH-SY5Y cells. J Korean Neurosurg Soc. 2007:42:392-9.

53. Luo T, Zhang H, Zhang W-W, Huang J-T, Song E-L, Chen S-G, He F, Xu J, Wang $\mathrm{H}-\mathrm{Q}$. Neuroprotective effect of Jatrorrhizine on hydrogen peroxideinduced cell injury and its potential mechanisms in PC12 cells. Neurosci Lett. 2011;498:227-31.

54. Jhamandas JH, Wie MB, Harris K, MacTavish D, Kar S. Fucoidan inhibits cellular and neurotoxic effects of $\beta$-amyloid $(A B)$ in rat cholinergic basal forebrain neurons. Eur J Neurosci. 2005;21:2649-59.

\section{Submit your next manuscript to BioMed Central and we will help you at every step:}

- We accept pre-submission inquiries

- Our selector tool helps you to find the most relevant journal

- We provide round the clock customer support

- Convenient online submission

- Thorough peer review

- Inclusion in PubMed and all major indexing services

- Maximum visibility for your research

Submit your manuscript at www.biomedcentral.com/submit 